Emerson A. Moffitt MD, Dhun H. Sethna MD, Richard J. Gray MD, Michele DeRobertis RN, Jack M. Matloff MD, John A. Bussell MD

\section{Rate-pressure product correlates poorly with myocardial oxygen consumption during anaesthesia in coronary patients}

In 26 patients having coronary grafts, haemodynamics, coronary sinus blood flow and the arterio-coronary sinus difference of oxygen content were determined, awake and at four intervals during morphine-oxy gen or halothaneoxygen anaesthesia. Rate-pressure product $(R P P)$, triple product (TP) and myocardial oxygen consumption $\left(\mathrm{MVO}_{2}\right)$ were calculated. The correlation of the two indirect indices to $\mathrm{MVO}_{2}$ were sested by repeated measures and regression analyses. No significant correlations were seen at four of five study times, when outlying data points were appropriately excluded. A piffall of using more than one data point from each palient in the linear regression analysis is pointed out. In addition to the lack of correlation of RPP to $\mathrm{MVO}_{2}, R P P$ was an imprecise predictor of myocardial lactate production and of postoperative infarction.

\section{Key words}

ANAESTHETICS, VOLATILE: halothane;

ANAESTHETICS, INTRAVENOUS: morphine; HEART: oxygen consumption, pulse rate, myocardial blood flow.

From the Department of Anesthesiology and Thoracic and Cardiovascular Surgery, Cedars-Sinai Medical Centre, Los Angeles, California.

Address correspondence to: E.A. Moffitt, MD, Sir Charles Tupper Medical Building, University Avenue, Halifax, Nova Scotia, B3H 4H7.
The accuracy, and hence usefulness, of indirect indicators of myocardial oxygen consumption $\left(\mathrm{MVO}_{2}\right)$ are currently of much interest in anaesthesia. A critical question is whether a simple determination such as rate-pressure product or triple product accurately reflect changes in $\mathrm{MVO}_{2}$. Are they useful predictors of myocardial ischaemia? Both heart rate and systolic blood pressure are major determinants of $\mathrm{MVO}_{2}$. Triple product (TP) also includes systolic ejection time, another factor in the rate of myocardial oxygen usage. Both Nelson et al. ${ }^{1}$ in awake, normal subjects, and Baller et $a l^{2}$ in awake patients with coronary disease, have reported close correlations of $\mathrm{MVO}_{2}$ and RPP

If this accuracy holds during anaesthesia, a valuable, simple means of monitoring $\mathrm{MVO}_{2}$ is readily available. There has been little information in anaesthetized patients until recently, bccausc of the difficulties of determining $\mathrm{MVO}_{2}$. In a study of patients with coronary disease, Wilkinson et al. ${ }^{3}$ reported a useful correlation $(r=0.78)$ of RPP to $\mathrm{MVO}_{2}$ during halothane or morphine anaesthesia. To further investigate this relationship, we mea sured coronary sinus blood flow (CSF) and calculated $\mathrm{MVO}_{2}$ in 26 patients having aorto-coronary bypass under halothane or morphine anaesthesia, using their methodology. ${ }^{3}$ We did not confirm a useful correlation of RPP or TP to $\mathrm{MVO}_{2}$.

\section{Patient population}

Our protocol had approval of the Human Subjects Committee of Cedars Sinai Medical Centre and the 26 patients gave their informed consent. Eighteen 
of these patients were the subject of a previous study of morphine or halothane anaesthesia. ${ }^{4}$ There were 20 males and six females whose mean age was 58 years with a mean weight of $77 \mathrm{Kg}$. Nineteen had previous myocardial infarction but all had wellpreserved ventricular function. Preoperative mean ejection fraction was 0.69 and mean left ventricular end-diastolic pressure (LVEDP) was $14 \mathrm{mmHg}$. Twenty-three were taking propranolol, most of them $80 \mathrm{mg}$ daily. Their disability by N.Y.H.A. classification was: Class II - 11, Class III - 10 and Class IV -5 . They had a mean of 3.8 vein grafts.

Criteria for exclusion were: valvular heart diseasc, cssential hypertension (diastolic > 105 $\mathrm{mmHg}$ ), diabetes mellitus, significant pulmonary disease, LVEDP $>20 \mathrm{mmHg}$ at rest and those within two weeks of myocardial infarction.

\section{Methods}

Premedication was secobarbital $\left(3 \mathrm{mg} \cdot \mathrm{kg}^{-1}\right)$ and morphine $\left(0.25 \mathrm{mg} \cdot \mathrm{kg}^{-1}\right)$. With local anaesthesia, we placed a radial arterial cannula and two thermodilution catheters, both via the Seldinger technique, into the right internal jugular vein. One was a triple lumen catheter ${ }^{5}$ floated into the pulmonary artery (Edwards, Santa Ana, California). The second was a special preshaped $7 \mathrm{Fr}$, catheter that was manipulated into the coronary sinus, guided by fluoroscopy. A series of measurements was done: (1) before induction of anaesthesia; (2) after induction; (3) after intubation; and (4) before and (5) after sternotomy.

Each series included a recording of blood pressure, electrocardiogram and pulse rate (VR 6 Electronics for Medicine), measurement of total coronary sinus flow ${ }^{6}$ and drawing of simultaneous blood samples (arterial and coronary sinus). From the latter, haemoglobin and oxygen saturation were determined by co-oximetry (Instrumentation Laboratory, Model 282) and lactate concentration, by the Marbach method. ${ }^{7}$ Systolic blood pressure and pulse rate were multiplied to obtain RPP. Systolic ejection time, measured from the record, was multiplied by the RPP to obtain the triple product. Coronary sinus flow was measured by a technique of continuous flow thermodilution. ${ }^{5}$

$\mathrm{MVO}_{2}$ was calculated in $\mathrm{ml} /$ minute from total $\mathrm{CSF}$ ( $\mathrm{ml} / \mathrm{min}$ ) and the arterial-coronary sinus difference of oxygen content ( $\mathrm{ml} \mathrm{O} / \mathrm{dl}$ ). $\mathrm{MVO}_{2}$ represents the oxygen consumption of the left

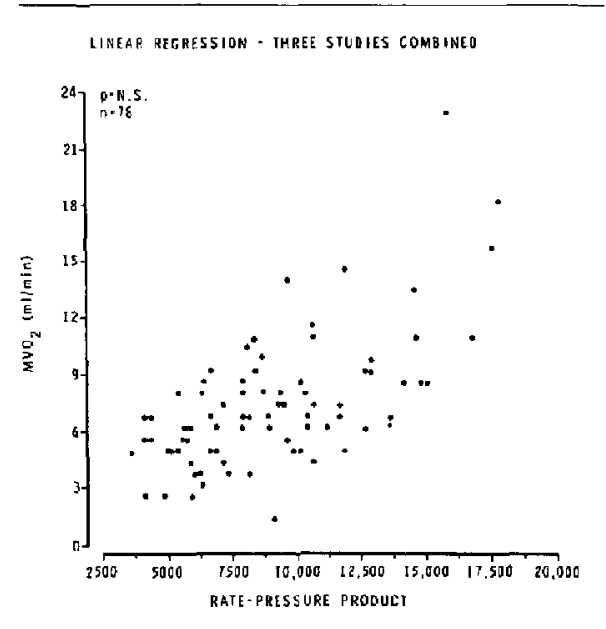

FIGURE 1 Regression analysis of $\mathrm{MVO}_{2}$ to ratc-pressure product, combining three studies: postincubation, prestemotony and poststemotomy.

ventricle drained by the coronary sinus, approximately 95 per cent of the free wall and septum. Lactate extraction or production, by the myocardium, was calculated in per cent, by the formula: Art-CS/Art, with Art and CS the arterial and coronary sinus concentrations of lactate in $\mathrm{mEq} / \mathrm{L}$.

Seventeen patients had halothane-oxygen anaes thesia and nine had morphine $\left(1 \mathrm{mg} \cdot \mathrm{kg}^{-1}\right)$ and oxygen. ${ }^{4}$ Induction with halothane began after a small dose of thiopental (mean $137 \mathrm{mg}$ ), while that with morphine included diazepam (mean $10.8 \mathrm{mg}$ ) before intubation. A mean dose of $7.8 \mathrm{mg}$ of pancuronium was given before intubation. Five patients in each of the two anaesthetic regimens were given intravenous propranolol $\left(0.1 \mathrm{mg} \cdot \mathrm{kg}^{-1}\right)$ an hour before induction.

\section{Statistical analyses}

Analysis of repeated measures and regression analyses were done separately for each of the five study series, from the awake state through posternotomy, using (1) RPP and $\mathrm{MVO}_{2}$, and (2) TP and $\mathrm{MVO}_{2}$. In addition, each linear regression model was calculated with all data, as well as excluding any data points (outlier's), distant from the main group. Statistical significance was accepted as $\mathrm{p}<$ 0.05 . 


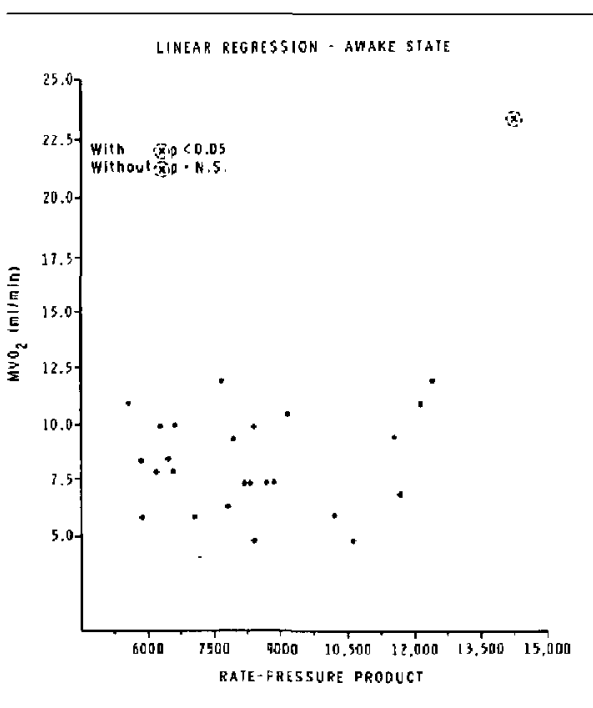

FIGURE 2 In the awake state, the correlation of $\mathrm{MVO}_{2}$ to rate-pressure product is $p<0.05$ when onc outlying point is included; no significance is present without it.

\section{Results}

Figures 1-6 present the linear regression analysis of $\mathrm{MVO}_{2}$ to RPP or TP at the five sequential times of study. Since the statistical results were the same for both RPP and TP in each study, only one is presented.

The 78 data points from three studies (postintubation, presternotomy, poststernotomy) in the 26 patients are plotted together in Figure 1. In the awake state (Figure 2) the relationship of $\mathrm{MVO}_{2}$ and $\mathrm{RPP}$ reached $\mathrm{p}<0.05$ with one outlier included but is not significant when excluding it. The correlation coefficient ( $r$ ) for the 26 data points was 0.45 , but only 0.09 with the outlier omitted. Similarly, postinduction (Figure 3) there is a significant correlation of $\mathrm{MVO}_{2}$ and RPP only when one outlier is included. The $r$ value for 26 points was 0.52 ; without the outlier, $r=0.04$. Postintubation (Figure 4), $\mathrm{MVO}_{2}$ and TP show a significant relationshp when three outliers are included, but not without them. With all 26 points, $r=0.62$; with 23 points included, it was 0.32 . The only time that $\mathrm{MVO}_{2}$ and TP (or RPP) showed a significant correlation both with and without outliers (two), was prestemotomy (Figure 5). The r value includ-

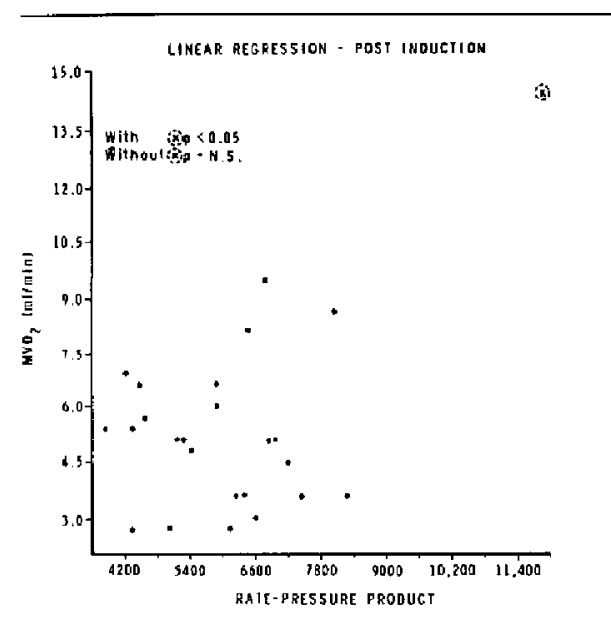

FIGURE 3 After induction of anaesthesia, the correlation is significant only when one distant outlier is included.

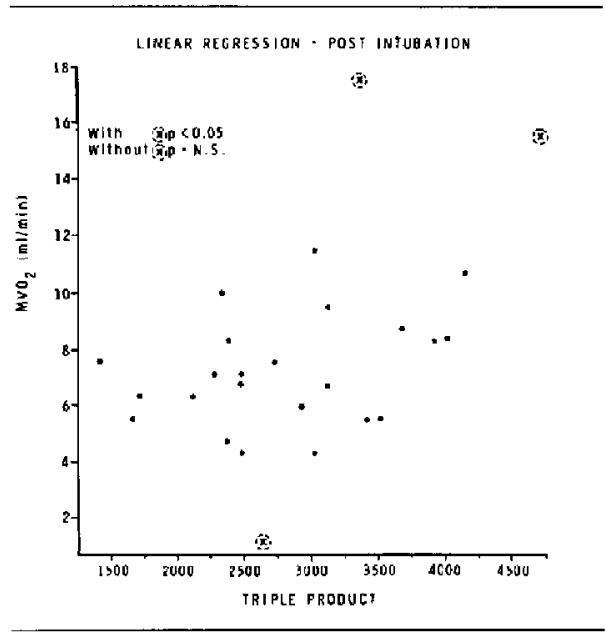

FIGURE 4 Postintubation, $\mathrm{MVO}_{2}$ is correlated $(\mathrm{p}<0.05)$ to triple product, when three outliers are included but not with their exclusion.

ing outliers was 0.75 and without them $r=0.73$. Poststernotomy (Figure 6), the presence or absence of one outlier also changed the statistical correlation from $\mathrm{p}<0.05$ to non-significance. The $\mathrm{r}$ value with 26 points included was 0.55 ; without the outlier, $r=0.38$ 


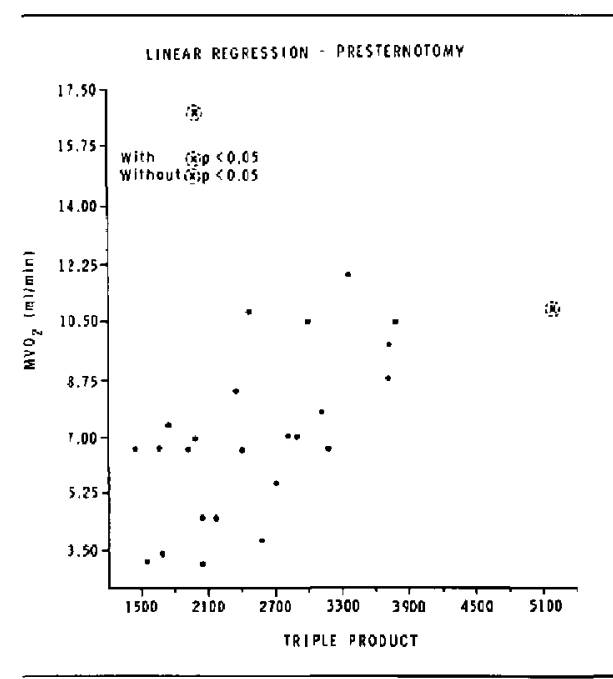

FIGURE 5 The presternotomy study was the only time that $\mathrm{MVO}_{2}$ and triple product were significantly corrclated in the absence of two outlying points.

The only outlying data point in three of the studies (awake, postinduction and poststemotomy), plus one of three outliers at postintubation and one of two outliers at prestemotomy, i.e., five of all eight outlying data points, came from one patient. The Table provides detailed information on the variables from which RPP and $\mathrm{MVO}_{2}$ were derived, at each study time in this patient. His blood pressure, pulse rate and hence RPP, were elevated throughout; his above-normal CSF at all study times led to greatly increased $\mathrm{MVO}_{2}$ calculations.

Lactate extraction by the myocardium was present at all times except poststernotomy in two patients, who received morphine anaesthesia and in one having halothane. ${ }^{4}$ No changes in ST segment configuration were noted at any time, although continuous recording was not done. Three patients had EKG and enzymatic evidence of mild infarction postoperatively, in addition to one patient who infarcted during the pump-run. ${ }^{4}$

\section{Discussion}

Patients with significant coronary disease have definite limitations to myocardial oxygen supply. Increases in heart rate and blood pressure from sympathetic stimulation during anaesthesia have great potential for exceeding the limits of that oxygen supply. If we are to avoid unidentified periods of intraoperative ischaemia a simple means of assessing myocardial oxygenation is clearly needed. Unfortunately, neither $\mathrm{MVO}_{2}$ nor biochemical evidence of myocardial ischaemia (lactate production) is readily available in the operating room.

The possible usefulness of rate-pressure product as such a practical monitor came from cardiology. In 10 normal exercising subjects, Nelson et al. ${ }^{\prime}$ reported in 1974 that $\mathrm{MVO}_{2}$ correlated best with the product of heart rate and blood pressure (correlation coefficient $=0.88$ ). Heart rate alone correlated better with $\mathrm{MVO}_{2}(\mathrm{r}=0.82)$ than did tension time index or triple product $(r=0.68)$. Baller et al. ${ }^{2}$ in 1980 found in 13 awake patients with coronary discase high degrees of correlation of $\mathrm{MVO}_{2}$ with tension time index $(r=0.93), \operatorname{RPP}(r=0.91)$ and with TP ( $r=0.94$ )

Little quantitative information on anaesthetized patients has come forth because there have been few studies of coronary flow and arterio-coronary sinus difference of oxygen content, the two components of $\mathrm{MVO}_{2}$. Until recently, these have been relatively impractical to measure in the surgical suite.

In 1979, Sonntag ${ }^{8}$ reported a poor correlation ( $r=0.50$ ) of RPP to $\mathrm{MVO}_{2}$ in seven healthy

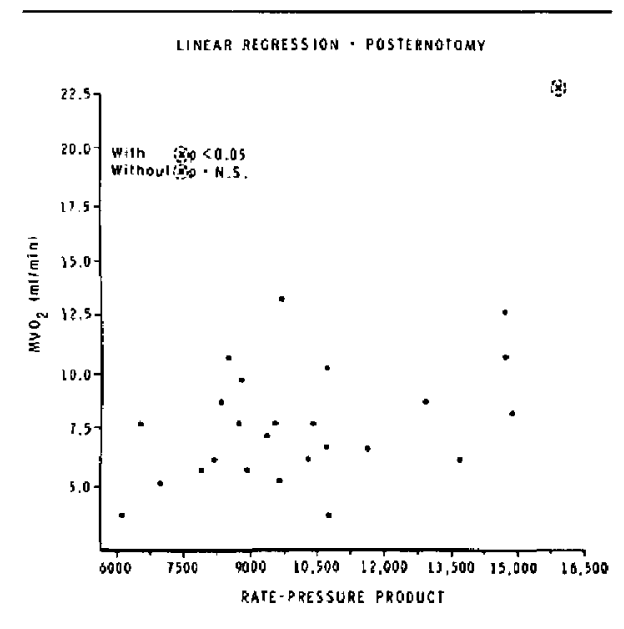

FIGURE 6 After stemotomy, $\mathrm{MVO}_{2}$ and rate-pressure product showed no correlation when an outlier was omitted. 
TABLE

\begin{tabular}{|c|c|c|c|c|c|c|}
\hline & $\begin{array}{l}M A P^{*} \\
m m H g\end{array}$ & $\begin{array}{l}\text { Heart rate } \\
\text { beats/mith. }\end{array}$ & $R P P$ & $\begin{array}{l}C S F \\
\text { ml/min. }\end{array}$ & $\begin{array}{l}\mathrm{A}-\mathrm{VO} \mathrm{O}_{2} \\
\text { difference } \\
\text { mll } 100 \mathrm{ml}\end{array}$ & $\begin{array}{l}M V O_{2} \\
\mathrm{ml} / \mathrm{min} .\end{array}$ \\
\hline Awake & 116 & 85 & 14,280 & 177 & 13.2 & 23.4 \\
\hline Postinduction & 97 & 89 & 11,926 & 151 & 8.8 & 14.2 \\
\hline Postintubation & 110 & 120 & $\begin{array}{l}17,760 \\
(T P 3500)\end{array}$ & 180 & 9.9 & 17.8 \\
\hline Prestertiotomy & 106 & 94 & $\begin{array}{l}12,878 \\
(1 P 2100)\end{array}$ & 152 & 11.9 & 16.9 \\
\hline Poststemotomy & 105 & 119 & 16,025 & 188 & 12.2 & 22.9 \\
\hline
\end{tabular}

*Mean arteral pressure.

patients anaesthetized with halothane. Since the heart rate did not change, the best correlate of $\mathrm{MVO}_{2}$ was systolic pressure alone $(r=0.63)$. They measured coronary flow by an argon-washin technique. These same authors ${ }^{9}$ similarly found a poor correlation ( $r=0.66$ ) in nine patients with coronary disease, after high dose fentanyl $\left(100 \mu \mathrm{g} \cdot \mathrm{kg}^{-1}\right)$.

Wilkinson et al. ${ }^{3}$ also reported, in 1979, the study of 16 paticnts having coronary grafting, during morphine or halothane anaesthesia, using the same thermodilution method for coronary sinus flow as we did. They found $\mathrm{MVO}_{2}$ and RPP to have a useful correlation ( $r=0.78$ ). Subsequently these workers ${ }^{10}$ reported a good correlation of $\mathrm{MVO}_{2}$ and RPP during morphine in dogs $(r=0.71$ ) or morphine-halothane $(r=0.84)$ anaesthesia. They concluded that RPP is the best correlate of $\mathrm{MVO}_{2}$ over a wide range of ventricular afterload states under morphine-halothane anaesthesia.

Our present communication emanated from a study ${ }^{4}$ of coronary flow and $\mathrm{MVO}_{2}$, before and during morphine or halothane anaesthesia, for coronary grafting. We examined the correlations of $\mathrm{MVO}_{2}$ to RPP and TP, before induction of anaesthesia and at four times during anaesthesia, before extracorporeal circulation, to re-examine the positive correlative findings of Wilkinson, ${ }^{3}$ using these same anaesthetic regimens and investigative techniques.

In essence we found that significant correlation of $\mathrm{MVO}_{2}$ to RPP (ot TP) depends upon the precise details of the statistical analysis. Our analyses were done by repeated measures, regression analyses, on the data obtained at each separate study, with patients awake and at four different times during anaesthesia.
A regression model ${ }^{11}$ consisting of one dependent variable and one independent variable can be written as:

$\mathrm{Yi}=\mathrm{Bo}_{\mathbf{o}}+\mathbf{B i X i}+\mathbf{E} \mathbf{i}$

where

$Y i=$ value of the dependent variable for the $i^{\text {th }}$ observation;

$\mathrm{BO}$ and $\mathrm{Bi}=$ the regression parameters;

$\mathrm{Xi}=$ value of the independent variable for the $i^{\text {th }}$ observation;

and

$\mathrm{Ei}=$ the random error term for the $\mathrm{i}^{\text {th }}$ observation.

One of the assumptions of the regression model concerns the error term Ei. It is assumed that these errors are normally distributed, with mean, $\mu=0$ and variance $\mathrm{O}^{2}$. Additionally, the model assumes that the error for each observation, is independent of the error terms for other observations. If this assumption of independence is violated, i.e., the error terms are dependent, the estimated regression parameters, $\mathrm{Bo}$ and $\mathrm{Bi}$, are still unbiased, but standard deviation may be underestimated, affecting tests of significance. The effect is to decrease the $\mathrm{p}$ value and increase the likelihood of significance.

In our study, several measures were obtained for each subject under different conditions: a repeated measures design. It seems reasonable to assume that for any given subject these measures will be correlatcd. When we include the data points from each subject at several sequential study series, in a single regression analysis, it is likely that we 
are violating the assumption of independent error terms.

That situation is exemplied in Figure 1, with data combined from three of our series during anaesthesia. Since it is incorrect to do significance tests on pooled data, we can draw no conclusions as to corrclations. Contrast this with the study of Wilkinson $e t a l .^{3}$ They found a $\mathrm{p}<0.05$ correlation of $\mathrm{MVO}_{2}$ and RPP, both expressed as percent of control with an $r=0.78$. However, they analysed together, data from two studies (postintubation and poststernotomy) on the same patients. Their positive correlation of RPP and $\mathrm{MVO}_{2}$ may have been due to this pooling of non-independent data.

The linear regression analysis for each of our separate studies illustrates another statistical pitfall: the use of outliers. In all but one study, omitting data points that are far from the clustered remainder, destroyed the significant correlation of $\mathrm{MVO}_{2}$ to RPP or TP. We believe that removal of outliers in our data is a statistically conservative technique designed to reduce a spuriously inflated $r$ value. It is possible that Wilkinson's findings were influenced by the inclusion of outliers.

However, outlying points should have an explanation for their distance from the remaining population and hence justification for their noninclusion in the statistical analyses. That is possible for five of the eight outliers in the five sequential studies. Those points were all from one patient who was different from the other 25 preoperatively and who behaved differently during anaesthesia. He was younger ( 46 years), by far the most obese $(111 \mathrm{Kg})$ with a history of heavy smoking and alcohol intake; he was not taking a beta-blocking drug. For the whole group the mean age was 58 years and weight $77 \mathrm{Kg}$. Twenty-three of the remaining 25 patients were on propranolol. This patient at the awake study in the operating room, had a higher blood pressure, heart rate and coronary flow (by 50 per cent) than average for the group; his $\mathrm{MVO}_{2}$ at that time was double the average ${ }^{4}$ Halothane-oxygen anaesthesia was not successful in depressing the MAP, CSF or $\mathrm{MVO}_{2}$. The increase in heart rate reflected the absence of beta block. Consequently the calculated RPP and $\mathrm{MVO}_{2}$ remained high throughout the sequence of studies. This patient was clearly of a different population with a different response to anaesthesia. Hence data from his study ought not to be included. Without it there are no positive correlations at four of the five study times, including the awake premedicated state. We can discern no specific reasons for the presence of the other three outlying data points.

Barash $^{12}$ has reviewed the use and limitations of RPP as a criterion of adequacy of myocardial oxygenation, pointing out the separate effects of rate and systolic pressure changes. The latter may explain why good correlation of $\mathrm{MVO}_{2}$ to RPP has been documented in awake patients and not by us during anaesthesia. The responses of the circulation to exercise include increased cardiac output and heart rate and reduced peripheral resistance. The circulatory responses to the anaesthetic state are accepted as decreased contractility with less change in rate. In this present study, total peripheral resistance fell upon induction with both agents and remained at awake, nomal level during the remainder of the period. ${ }^{4}$ So increased resistance was not a factor in the lack of correlation. In addition, sympathetic stimulation (intubating and surgical), introduces another set of responses that alter afterload and ventricular filling time. Possibly the reduction of the usual sympathetic response during adequate anaesthesia blunts the increase in $\mathrm{MVO}_{2}$ that should take place from increased blood pressure and heart rate.

We must consider whether the lack of correlation may be due to imprecision on the $\mathrm{MVO}_{2}$ side of the equation, rather than the RPP side. The technique of CSF measurements is closely reproducible in our hands. In 12 awake patients, duplicate flow measurements done three minutes aparl, were $113.8 \pm$ 0.01 and $112.9 \pm 0.1 \mathrm{ml} /$ minute (unpublished data). Determinations of haemoglobin and oxygen saturation are similarly accurate. What is less sure is the interpretation of oxygen content of coronary sinus blood as an indicator of ischaemia. That blood is a pool from all areas of left ventricular muscle. Significant deficits of oxygen in some segments could be masked by adequate oxygen in blood from well-perfused areas. A decreased in CS oxygen content likely means that a large proportion of ventricle is ischaemic; one must look for lactate production to verify this. So our present ability to document the state of oxygenation of ventricular muscle is hampered by the inability to draw conclusions as to regional oxygenation. Perhaps 
documenting only global oxygen consumption is not sufficiently precise to demonstrate a correlation with RPP.

In our study the three patients, with clear evidence of myocardial ischacmia (lactate production) after sternotomy, had RPPs of $6,120,13,800$ and 16,025 . The three patients, with evidence of mild infarction postoperatively, had a RPP poststernotomy of $6,510,12,900$ and 13,800 , with only the latter showing myocardial lactate production at any measured time prepump. ST segment changes were not seen in any of the 26 patients.

We lound that rate-pressure product or triple product and $\mathrm{MVO}_{2}$ correlates poorly, both when awake and during anaesthesia. Given the RPP, it is virtually impossible to estimate or predict $\mathrm{MVO}_{2}$. Also given the RPP in an abnormal range, it seems unlikely that one can predict the presence of an abnormal $\mathrm{MVO}_{2}$. Wc conclude that RPP is not a precise indicator of the state of myocardial oxygenation in the anaesthetized patient. We see, as yet, no simple monitoring predictor of when, in the course of increasing heart rate and blood pressure, potentially irreversible myocardial ischaemia occurs in coronary patients. In the absence of such information, keeping heart rate and blood pressure at, or below, awake values seems the safest course.

\section{Acknowledgements}

We thank the cardiac surgeons for their co-operation and agreement to study their patients, Dr. Harvey Brown for performing the co-oximetry determinations and Jo-Ann Prause for invaluable aid in statistical analysis.

\section{References}

1 Nelson $K R$, Gobel FL, Jorgensen CR, Wang $K$, Wang $Y$, Taylor HL. Hemodynamic predictors of myocardial oxygen consumption during static and dynamic exercise. Circulation 1974; 50: $1179-89$

2 Baller D, Schenk H, Strauer BE, Hellige $G$. Comparison of myocardial oxygen consumption indices in man. Clin Cardiol 1980; 3; 116-22.

3 Wilkinson PL, Moyers JR, Ports T, Chatterjee K, Ullyou $D$, Hamilton WK. Rate-pressure product and myocardial oxygen consumption during surgery for coronary artery bypass. Circulation Suppl Cardiovasc Surg 1979; 60: I-170-3.

4 Moffitt EA, Sethna DH, Bussell JA, Raymond M, Matloff JM, Gray RJ. Myocardial metabolism and hemodynamic responses to halothane or morphine anaesthesia for coronary artery surgery. Anesth Analg 1982; 61: 979-85.

5 Swan HJC, Ganz W, Forrester IS, Marcus $H$, Diamond $G$, Chonette $G$. Catheterization of the heart in man with use of a flow-directed, balloontipped catheter. N Eng J Med 1973; 283: 447-50.

6 Ganz W, Tamura $K$, Marcus HS, Donosa R, Yoshida $S$. Swan HJC Measurement of coronary sinus blood flow by continuous thermodilution in man. Cireulation 1971; 44: 181-95

7 Marbach EP, Weit MH. Rapid enzymalic measurements of blood lactate and pyruvate. Clin Chem 1967; 13: 314-25.

8 Sonntag H, Merin RG, Donath U, Radke J, Schenk $H$-D. Myocardial metabolism and oxygenation in man awake and during halothane anesthesia. Aresthesiology 1979; 51: 204-10.

9 Sonntag, $H$, Larsen $R$, Hilfiker $O$, Ketler $D$, Brockschneider $B$. Myocardial blood flow and oxygen consumption during high-dose fentanyl anaesthesia in patients with coronary artery disease. Anesthesiology 1982; 56: 417-22.

10 Wilkinson PL, Tyberg JV, Moyers JR, White AE. Correlates of myocardial oxygen consumption when afterload changes during halothane anesthesia in dogs. Anesth Analg 1980; 59: 233-9.

11 Neter J, Wasserman W. Applied Linear Statistical Models, Richard D. Irwin, Inc., Homewood, Illinois (1974).

12 Barash $P G$, Kipriva $C J$. The rate-pressure product in clinical anesthesia. Boon or bane? Anesth Analg 1980; 59: 229-31. 
Résumé

Chez 26 malades opérés pour pontage aorto-coronaive, nous avons mesuré le profii hémodynamique, le flux sanguin du sinus coronaire et la différence artérioveineuse en oxygène du sang coronaire. Des mesures ont été faires avant l'anesthèsie et à quatre reprises durant une anesthésie à la morphine-oxygène ou halothameoxygène. Le produit fréquencelpression (RPP) le triple produit (TP) et la consommation d'oxygène par le myocarde $\left(\mathrm{MVO}_{2}\right)$ ont été calculés. La corrélation des deux index indirects de $\mathrm{MVO}_{2}$ a été vérifié par des mesures répétées et par des analyses de courbe de régression. Aucune corrélation significative n'a été démontrée d̀ quatre des cinq stations de mesure, lorsque les données aberrantes ont été exclues des calculs. Dans la discussion, nous exposons le danger qu'il y a d'introduire pour chaque patient plas d'une donnée dans l'analyse de régression.

En plus d'être un pauvre indicateur de consommation d'oxygène par le myocarde, le RPP était un informateur imprécis quanu à la praduction de lactate par le myocarde et l'incidence de l'infarctus post-opératoire. 